\title{
A Randomized Colorectal Cancer Screening Intervention Trial in the Iowa Research Network (IRENE): Study Recruitment Methods and Baseline Results
}

\author{
Jeanette M. Daly, RN, PhD, Yinghui Xu, MS, John W. Ely, MD, MSPH, \\ and Barcey T. Levy, $P h D, M D$
}

Background: Only about half of eligible Americans are adherent with colorectal cancer (CRC) screening. Because patients generally access CRC screening via their primary care physicians, interventions to improve screening should be tested in the primary care setting. This article describes the recruitment and baseline characteristics of patients from 16 practice-based research network practices for a study to improve CRC screening.

Methods: A total of 8327 invitations were mailed to patients of these practices, and 1685 returned consent forms and baseline surveys.

Results: Of those who consented, 942 were up to date with screening, which indicates that office databases were unable to provide information about those who were already screened. The $\mathbf{7 4 3}$ due for screening were younger (mean age, 61 vs. 63 years), less likely to have an immediate family member with CRC (11\% vs. $19 \%)$, less likely to have Medicare (29\% vs. $40 \%)$, more likely to have no insurance (5\% vs. 1\%), and less likely to report a physician/nurse recommendation for CRC screening (63\% vs. 92\%) for all comparisons.

Conclusions: Our experiences for this practice-based research network randomized clinical intervention trial may be useful to others. Practice and patient recruitment processes were onerous with institutional review board issues, poorly prepared patient databases, and discarding of mail by the US Postal Service. (J Am Board Fam Med 2012;25:63-72.)

Keywords: Cancer Screening, Colorectal Cancer, Family Medicine Research, Practice-based Research

National clinical guidelines recommend colorectal cancer (CRC) screening for average-risk individuals beginning at age 50, yet fewer than half of all eligible Americans comply with these guidelines. ${ }^{1,2}$ Compliance rates are markedly lower for rural patients and individuals of low socioeconomic status. ${ }^{3}$

This article was externally peer reviewed.

Submitted 15 February 2011; accepted 15 August 2011.

From the Department of Family Medicine, the University of Iowa, Iowa City, IA.

Funding: We gratefully acknowledge the support of the American Cancer Society (Research Scholar Grant targeted, 08-148-01; CPPB, BTL) and the Department of Family Medicine, University of Iowa.

Trial Registration clinicaltrials.gov identifier: NCT01477814

Conflict of interest: none declared.

Corresponding author: Jeanette M. Daly, the Department of Family Medicine, the University of Iowa, Iowa City, IA (E-mail: jeanette-daly@uiowa.edu).
Because patients generally access CRC screening via their primary care physicians, interventions to improve screening should be tested in the primary care setting.

Recruitment of subjects in randomized controlled trials is the "process of screening and enrolling a predetermined number of subjects within a planned time." ${ }^{4}$ Recruitment of subjects in clinical trials is known to be difficult. ${ }^{5}$ For this study, recruitment started at the family physician office level, that is, to determine if offices would be willing to have their patients involved in a research study. This adds another level of complexity to the recruitment process.

Description of research studies in practice-based research networks have been described but include little description of physician office recruitment. ${ }^{6-9}$ 
The importance of participatory research is acknowledged as the potential for a bridge between science and practice through community engagement. ${ }^{10,11}$ Practice recruitment is a critical step for participatory research involving primary care practices in which many barriers impact participation, including project topic, recruitment process, office time demands, institutional requirements, resource limitations, scheduling meetings, staffing, space, and time. ${ }^{12}$

Thus, some challenging aspects of conducting a randomized CRC screening intervention trial in a family physician practice-based network include recruitment of family physician offices, recruitment of patients, and tracking all mailings and questionnaire returns. The purpose of this article is to describe the recruitment of 16 practices and patients for a randomized intervention study to improve CRC screening. We describe the baseline information from consenting subjects. Eligible patients were those due for CRC screening by selfreport and ineligible patients were those who selfreported being up to date with screening.

The overall purpose of the study was to enroll patients from 16 family medicine practices in a randomized clinical intervention trial to test office reminder systems of gradually increasing intensity to ensure that the patient was educated about CRC screening and received a physician recommendation for screening. Our goal was to invite 530 patients (265 men and 265 women) from each of 15 different offices to participate in the study, with the goal of recruiting 100 unscreened patients or patients due for screening from each office. Enrolled patients due for screening within each practice were randomized with equal chance to one of 4 groups: (1) usual care; (2) physician chart reminder alone; (3) physician chart reminder and multifaceted mailed patient education materials, including a self-completed CRC screening preference sheet, CRC screening reminder magnet, and a fecal immunochemical test (FIT) kit; or (4) all of the preceding plus a telephone reminder from research project staff. The main study outcome was for unscreened individuals to receive CRC screening by any one of the 4 nationally recommended tests.

\section{Methods}

This research was conducted in the Iowa Research Network (IRENE), established in 2001. At the time of recruitment for this study IRENE had 277 primary care physician members practicing in 150 offices in 72 of Iowa's 99 counties. IRENE's mission is to create new knowledge with relevance to rural primary care clinicians and their patients, with the outcome of improving the care of patients. Practice-based research networks, ${ }^{13}$ such as IRENE, are ideal settings for the much-needed research in realworld settings necessary to "provide translation of efficacy-tested interventions into effectiveness trials in clinical practice or broader evaluations of programs combining multiple interventions." ${ }^{14}$ At the time of the grant proposal submission in 2008, 58 practices (composed of 222 physicians) provided a letter of support.

After notification of funding for this project was received in the spring of 2008 , we randomly selected 15 family physician practices from the 27 family physician practices (of the original 58 practices) located in rural counties with a median per capita income level below the state average. We selected from practices in counties with a per capita income below the state average to increase the likelihood of inviting individuals of lower socioeconomic status to participate in the study.

Each office administrator designated a "CRC study coordinator" and that person received human subjects training via the Collaborative Institutional Training Initiative program. One practice was unable to participate at the time the study was initiated and another practice was randomly chosen to replace it. Each office's privacy officer signed a partial Health Insurance Portability and Accountability Act (HIPAA) waiver form so the research team could conduct the patient recruitment mailings. Invitation letters were mailed on office letterhead with the office's health care providers' electronic signatures.

Each office provided a list of patients between the ages of 52 and 79 years. We used a minimum age of 52 so that there would be no question that all patients were at the minimum age for initiating CRC screening. At the time the study was initiated, there was no upper age limit specified in national guidelines, but we felt that once many individuals reach the age of 80 years, more serious health conditions might take precedence. Surprisingly, despite the fact that 8 offices had electronic medical records, no office was able to generate a list of individuals due for CRC screening. After subjects were enrolled, each CRC study coordinator was 
responsible for placing a CRC screening chart reminder on the medical record of subjects randomized to the chart reminder intervention. This reminder was entitled "colorectal cancer screening reminder" and was printed on a $3-\times 4$-inch sticky note pad. The offices with electronic records programmed this as a "pop up" reminder. FITs were returned to the University of Iowa research team, developed, and results were mailed to each CRC study coordinator and patient, along with patient preferences for CRC screening modality. Those with a positive FIT were advised to schedule a colonoscopy. One year into the study, the study coordinator facilitated a medical record review by the research team.

Compensation to offices for participating in the study was $\$ 1,000$ each year for 3 years after major milestones had been accomplished. Study coordinators were compensated $\$ 200$ for completing the human subject education, and \$200 was provided for completion of the Federalwide Assurance paperwork. Offices were reimbursed for the costs of office stationery.

\section{Institutional Review Board Approval}

The initial institutional review board (IRB) application was submitted in May 2008, with one practice listed, and was approved in July 2008. The approval of the first office was straightforward because that practice already had their Federalwide Assurance approved by the US Department of Health and Human Services Office for Human Research Protection. The Federalwide Assurance ensures there is an IRB of record for each research project conducted. Because additional practices obtained their Federalwide Assurance and HIPAA privacy rule waiver of authorization (needed for patient lists to be sent to investigators), modifications were made to the IRB application to add the additional practices. We knew that it would take significant time to get all offices approved and thus made the decision to add offices to the IRB application one at a time. The University of Iowa IRB was the IRB of record for 12 practices, and 3 practices had their own IRB. The study team completed and submitted applications for those 3 sites. Once the study was approved at the external sites, the respective approval information was added to the University of Iowa IRB application. Enrollment and IRB approval for all offices was completed over a 17-month time period.

\section{Study Information Site Visits}

Before subject recruitment, the principal investigator (BTL) or a co-investigator (JWE) visited each office in person and provided the physicians and staff with a 50-minute standardized seminar about CRC screening and the study purpose and guidelines before initiating the study in a given office. A packet of information was given to each provider that included a baseline physician survey, 2 informed consents (one for them to keep), CRC screening pocket card (created by BTL), US Preventive Services Task Force $^{15}$ and American Gastroenterological Association $^{16}$ CRC screening guidelines, and a diagram showing the study flow for the project.

\section{Study Population}

A 2-step process was used for subject eligibility. First, practices provided patient lists of individuals between the ages of 52 to 79 years. From these lists, individuals living in nursing homes were excluded because of concerns about overall health status and potential ability to give informed consent. A random sample of 530 individuals (half men) was selected from each practice's list and invited to participate, with the goal of enrolling 100 unscreened patients from each practice in the study. To be eligible, individuals had to be due for CRC screening, which was determined by patient self-report to questions on the baseline survey about each specific CRC screening method and when this was most recently performed. Being due for CRC screening meant that no fecal occult blood test or FIT had been conducted within the past year, no barium enema or flexible sigmoidoscopy had been completed within the past 5 years, and no colonoscopy had been completed within the past 10 years, consistent with national guidelines. ${ }^{15,16}$

\section{Subject Recruitment}

Even though electronic files with names and addresses were generated by offices and sent to the University of Iowa Research Team, specific CRC screening information was not able to be generated. Thirteen of the offices provided the electronic file via an email attachment in a database format. One practice sent their electronic file on a passwordprotected compact disc. Another clinic was unable to create a file, so a research team member drove to the practice and created and downloaded the file.

Once electronic files were received, they were checked for duplicate names, incomplete addresses, 
ages outside the age range, missing or incomplete telephone numbers, nursing home residence, and addresses that were in another state (other than border states). From each clinic's electronic list, 530 subjects (when there were enough subjects) were randomly selected for inclusion in the study: 265 men and 265 women. Four offices were unable to provide a full list of 530 potential subjects. Before the mailing process, each practice's potential subject list was sent to the University's mail room for address cleansing and verification. The US Postal Service now requires bulk mailers to update their mailing lists every 90 days using an approved system. All presorted or automated mailings must comply to receive bulk mail postage discounts. A software program matches addresses to the US Postal Service's national database of known addresses, thus cleansing the address lists. Through this United States postal service process, most incorrect addresses or address updates were corrected. ${ }^{17}$

Recruitment for all offices was completed over a 26-month time period (December 2008 to February 2010). It was anticipated that the initial invitation letters would be sent to 530 subjects from each of the 15 participating practices, for a total of 7950 letters. However, 4 offices did not have enough subjects to meet the minimum of 530 randomized subjects to invite to participate; therefore, a satellite office of one of the practices (the physician provider was the same person seeing patients at 2 sites) was added to the list of participating offices, resulting in 8372 subjects invited to participate from a pool of 56,015 patients from 16 offices (see Table 1 and Figure 1).

Mailings for each office followed a modified Dillman approach and were initiated after IRB approval and sequenced over time. ${ }^{18}$ A 1-page prenotice letter was sent to all selected subjects on individualized office letterhead with electronic signatures of the office providers and the principal investigator of the study. Two weeks after the prenotice letter was mailed, a full packet of material was sent, which included a cover letter on office letterhead, a baseline questionnaire, a $\$ 2$ bill, postage-paid return envelope, and 2 informed consents (one for the subject to keep). Nonresponders were sent a reminder letter 3 weeks later. Within 2 to 6 weeks after the reminder letter was mailed, up to 4 telephone calls were made to nonresponders at various times of the day using standardized scripts to de-

Table 1. City Location and Population for Each Practice Site and Number of Subjects Eligible for Recruitment

\begin{tabular}{|c|c|c|c|c|c|c|}
\hline Office City & $\begin{array}{c}\text { City } \\
\text { Population }\end{array}$ & $\begin{array}{c}\text { Urban/Rural } \\
\text { Continuum Code* }\end{array}$ & Providers (n) & $\begin{array}{l}\text { Eligible Subjects, } \\
\text { Male/Female (n) }\end{array}$ & $\begin{array}{l}\text { Total Subjects for } \\
\text { Recruitment (n) }\end{array}$ & IRB \\
\hline Alcester, SD & 880 & 3 & 3 & $252 / 298$ & 550 & $\mathrm{U}$ of $\mathrm{I}$ \\
\hline Algona, IA & 5,741 & 7 & 12 & $3342 / 3338$ & 6680 & $\mathrm{U}$ of $\mathrm{I}$ \\
\hline Clinton, IA & 27,772 & 4 & 17 & $4012 / 4321$ & 8333 & $\mathrm{U}$ of $\mathrm{I}$ \\
\hline Corning, IA & 1,783 & 9 & 5 & $296 / 425$ & 721 & Own \\
\hline Dubuque, IA & 57,686 & 3 & 5 & $252 / 285$ & 537 & $\mathrm{U}$ of $\mathrm{I}$ \\
\hline Elk Point, SD & 1,714 & 3 & 3 & $403 / 389$ & 792 & $\mathrm{U}$ of $\mathrm{I}$ \\
\hline Grinnell, IA & 9,105 & 7 & 1 & $65 / 175$ & 240 & $\mathrm{U}$ of $\mathrm{I}$ \\
\hline Guttenberg, IA & 1,987 & 8 & 6 & $920 / 1020$ & 1940 & $\mathrm{U}$ of $\mathrm{I}$ \\
\hline Iowa Falls, IA & 5,193 & 6 & 1 & $132 / 142$ & 274 & $\mathrm{U}$ of $\mathrm{I}$ \\
\hline Le Mars, IA & 9,237 & 6 & 11 & $923 / 1015$ & 1938 & $\mathrm{U}$ of $\mathrm{I}$ \\
\hline Manchester, IA & 5,257 & 6 & 10 & $1883 / 1880$ & 3763 & $\mathrm{U}$ of $\mathrm{I}$ \\
\hline Muscatine, IA & 22,697 & 4 & 10 & $577 / 702$ & 1279 & $\mathrm{U}$ of $\mathrm{I}$ \\
\hline Sioux Center, IA & 6,002 & 6 & 13 & $2314 / 2271$ & 4585 & $\mathrm{U}$ of $\mathrm{I}$ \\
\hline Sioux City, IA & 85,013 & 3 & 28 & $1950 / 1911$ & 3861 & $\mathrm{U}$ of $\mathrm{I}$ \\
\hline Spencer, IA & 11,317 & 7 & 15 & $4014 / 4118$ & 8132 & Own \\
\hline West Burlington, IA & 3,161 & 5 & 10 & $5870 / 6520$ & 12390 & Own \\
\hline
\end{tabular}

*2003 rural-urban continuum codes: $1=$ counties in metro areas of 1 million population or more; $2=$ counties in metro areas of 250,000 to 1 million population; $3=$ counties in metro areas of fewer than 250,000 population; $4=$ urban population of 20,000 or more, adjacent to a metro area; $5=$ urban population of 20,000 or more, not adjacent to a metro area; $6=$ urban population of 2500 to 19,999 , adjacent to a metro area; $7=$ urban population of 2500 to 19,999 , not adjacent to a metro area; $8=$ completely rural or less than 2500 urban population, adjacent to a metro area; $9=$ completely rural or less than 2500 urban population, not adjacent to a metro area.

IRB, institutional review board. 
Figure 1. Subject recruitment process.

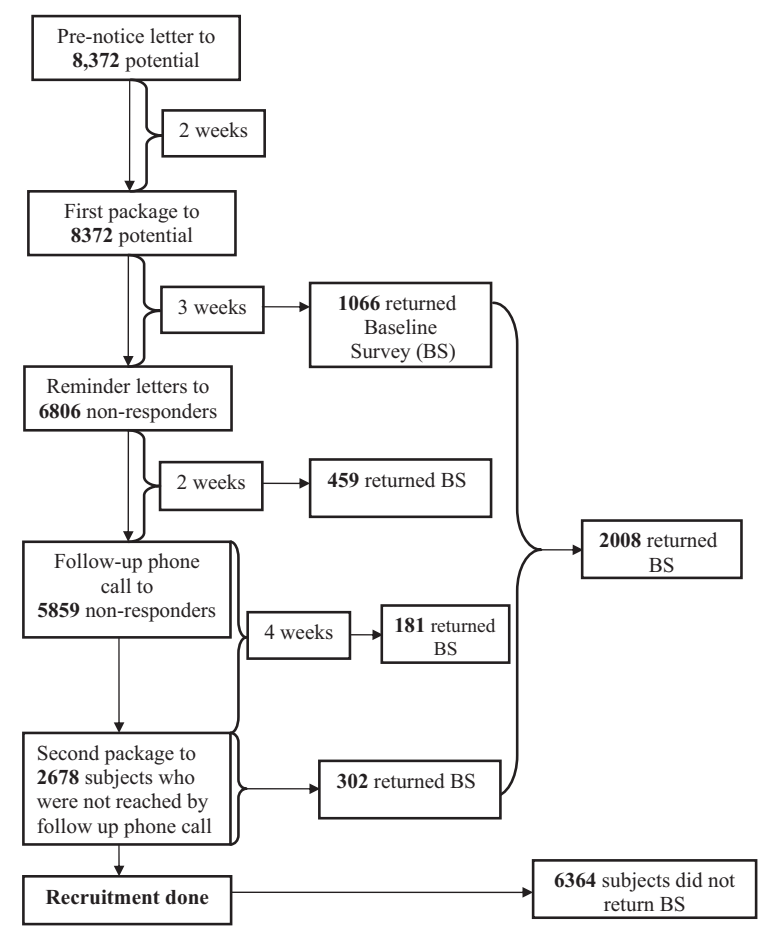

termine if the subjects would like to participate and to answer any questions. After the telephone calls were completed, a second full packet was sent to those persons who requested one and those who were not reached by telephone. Subjects who returned both an informed consent and a baseline questionnaire were mailed a \$20 check.

Subjects who returned only the questionnaire or informed consent were telephoned and asked if they wanted to complete the missing item. If desired, a duplicate questionnaire or informed consent form was mailed. If we were unable to reach the individual by telephone, then the missing items were mailed to them.

\section{Baseline Patient Questionnaire}

The 79-item questionnaire for the baseline survey was developed by investigators and has been tested extensively. ${ }^{19,20}$ The questionnaire had skip patterns if a specific CRC screening test had not been completed by a subject, such as barium enema and flexible sigmoidoscopy, so that no individual had to answer all 79 questions. Sections of the questionnaire included (1) demographics, (2) personal and family history of colon cancer or personal history of ulcerative colitis or Crohn disease, (3) exploring whether a health care provider had discussed CRC screening and the recency of this discussion, (4) recommendation for CRC screening and when it was completed for each specific CRC screening test, (5) reason for a specific test, (6) physician/ patient communication about CRC screening, (7) CRC screening readiness, (8) barriers to CRC screening, and (9) attitudes toward CRC screening. The items about CRC screening readiness, attitudes, and barriers to being screened for CRC were skipped if a subject was up to date with CRC screening. The full survey is available on request.

\section{American Cancer Society Database}

Two databases were created using Microsoft Access (Microsoft Corp., Redmond, WA): (1) a tracking database that included practice and patient information and that allowed tracking of the studyrelated activities (mailings, chart review trips, payments to practices, recruitment telephone calls, telephone calls for the intervention, subject payments, etc.); and (2) a second database that included all provider and patient questionnaires and medical record review information. In the tracking database, the office table was related to the patient table by virtue of the office ID field appearing in both tables. Office and patient screens were aligned next to each other so that while viewing a specific patient's information the corresponding office information was readily seen.

Databases were built by the study statistician (YX) with programming assistance from information technology staff. Research assistants requested updates as needed to maintain the flow and tracking for the study.

\section{Data Analysis}

Baseline questionnaires were double-entered in a Microsoft Access database and verified by an SAS program (SAS Institute, Inc., Cary, NC). Determination of eligibility was based on self-report of screening test completion and date. Means and frequencies were calculated. $\chi^{2}$ tests and $t$ tests were used as appropriate to compare the eligible and the ineligible groups. SAS version 9.1.3 was used for the analysis.

\section{Results}

Figure 1 shows the recruitment process. Prenotice letters and the first complete packet of study information were mailed to 8372 potential subjects, and 
1685 (20\%) returned both the informed consent and questionnaire. Based on their responses to the baseline questionnaire, 743 were eligible and enrolled in the study and 943 consented but were ineligible (see Figure 2).

Table 2 compares the subjects by eligibility status. Eligible subjects (those due for screening) were younger (mean age, 61 years vs 63 years for ineligible subjects); less likely to have an immediate family member with CRC (11\% vs 19\%); less likely to have Medicare (29\% vs $40 \%$ ); more likely to have no insurance ( $5 \%$ vs $1 \%$ ); and less likely to report a physician/nurse recommendation for CRC screening (63\% vs $92 \%)(P<.0001)$ for all comparisons. There were no differences in sex of subject or sex of health care provider between the 2 groups. Mean age at first recommendation for CRC screening was 53 years for both groups.

Table 3 shows the self-reported rates of recommendation and specific CRC tests completed by the 2 groups. Colonoscopy was the most frequently recommended CRC screening test for both groups, with $96 \%$ in the up-to-date group compared with $36 \%$ in the due for screening group $(P<.0001)$. For both groups, fecal occult blood test was the second most frequently recommended CRC screening test, followed by flexible sigmoidoscopy $(P<.0001)$ for both comparisons; barium enema and FIT were the least recommended tests $(P<.0001$ for both comparisons). Those who were up-to-date (and ineligible) reported higher rates of physician recommendation for each test $(P<.0001)$.

Figure 2. Eligibility of subjects who returned baseline survey (BS).

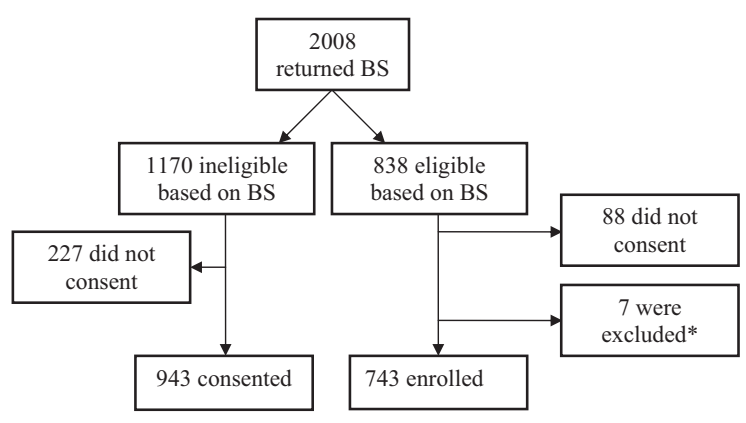

* 2 had colonoscopy, 2 not patients in clinic, 1 withdrew, 2 others.

\section{Discussion}

This article describes the baseline characteristics of a study population recruited from a primary care practice-based research network in a Midwestern state, including the challenges of recruitment. Despite the promise of electronic medical records, no office was able to generate a list of patients due for CRC screening. To determine CRC screening eligibility using electronic records, a complex algorithm that includes the appropriate time periods for each of the possible screening modalities would be needed. No office was able to generate such a list; thus, we decided to rely on patient self-report. Limitations of patient self-report are evident. In a recent study, the highest accuracy testing was for colonoscopy, and sensitivity of $82 \%$ and specificity of $95 \%$ for colonoscopy self-report and chart review were achieved. ${ }^{21}$

Subjects due for screening were quite similar to those up to date with screening in terms of sex, marital status, race, ethnicity, health status, and educational level. Those who were eligible (due for screening) were statistically significantly younger, had fewer relatives with CRC, were less likely to have Medicare (and more likely to have no insurance), and were less likely to have a physician recommendation for screening. These differences likely reflect less awareness about CRC and less insurance coverage for screening. Physician recommendation for screening has been shown to be highly predictive of CRC screening in numerous studies ${ }^{19,22-26}$; thus health care providers should have this conversation with all eligible patients. ${ }^{26,27}$ Other studies have found higher rates of family history of CRC and/or personal history of inflammatory bowel disease among those screened, likely because of heightened awareness of personal risk. ${ }^{28}$

When enrollment eligibility criteria includes not being screened for CRC, an unavoidable reason for not meeting total recruitment numbers is being up to date with screening. ${ }^{29}$ Despite the promise of electronic medical records, not a single participating office was able to generate a list of patients due for CRC screening. With the increasing emphasis on registries and creating a medical home, practices will have to step up their information technology capabilities. This will be important for primary care reimbursement and good clinical care. A limitation of the information technology at these practices was that the office study coordinators and informa- 
Table 2. Subject Demographics, History of Colon Cancer, and Health Care Provider Communication about Colorectal Cancer (CRC) Screening by Eligibility Status

\begin{tabular}{|c|c|c|c|}
\hline & $\begin{array}{l}\text { Up to Date with Screening } \\
\text { (Ineligible })(\mathrm{n}=942)\end{array}$ & $\begin{array}{l}\text { Due for Screening } \\
\text { (Eligible) }(\mathrm{n}=743)\end{array}$ & $P$ \\
\hline \multicolumn{4}{|l|}{ Demographics and history of colon cancer } \\
\hline Age & $63(7.06)$ & $61(6.95)$ & $<.0001$ \\
\hline \multicolumn{4}{|l|}{ Subject sex } \\
\hline Male & $431(46)$ & $355(48)$ & .397 \\
\hline Female & $512(54)$ & $388(52)$ & \\
\hline \multicolumn{4}{|l|}{ Health care provider sex } \\
\hline Male & $599(66)$ & $474(66)$ & .779 \\
\hline Female & $315(34)$ & $242(34)$ & \\
\hline \multicolumn{4}{|l|}{ History } \\
\hline Personal history of colon cancer & $31(3)$ & $5(1)$ & .0002 \\
\hline Immediate family member with colon cancer & $176(19)$ & $78(11)$ & $<.0001$ \\
\hline Distant relative with colon cancer & $172(18)$ & $83(11)$ & $<.0001$ \\
\hline Personal history of ulcerative colitis or Crohn's disease & $32(3)$ & $6(1)$ & .0004 \\
\hline Health status & & & .551 \\
\hline Very good/excellent & $449(57)$ & $256(54)$ & \\
\hline Good/fair & $337(42)$ & $211(45)$ & \\
\hline Poor & $8(1)$ & $7(1)$ & \\
\hline Marital status & & & .026 \\
\hline Single & $103(11)$ & $114(15)$ & \\
\hline Married & $750(80)$ & $571(77)$ & \\
\hline Widowed & $80(9)$ & $55(7)$ & \\
\hline Ethnicity & & & .331 \\
\hline Hispanic & $908(99)$ & $719(99)$ & \\
\hline Non-Hispanic & $6(1)$ & $8(1)$ & \\
\hline Race & & & .972 \\
\hline White & $926(99)$ & $733(99)$ & \\
\hline Non-white & $9(1)$ & $7(1)$ & \\
\hline Education & & & .285 \\
\hline High school or less & $323(35)$ & $273(37)$ & \\
\hline Some college & $290(31)$ & $203(28)$ & \\
\hline College or higher & $321(34)$ & $260(35)$ & \\
\hline Income & & & .008 \\
\hline$<\$ 40,000$ & $296(34)$ & $273(39)$ & \\
\hline$\$ 40,000$ to $<\$ 80,000$ & $392(45)$ & $319(46)$ & \\
\hline$\geq \$ 80,000$ & $179(21)$ & $104(15)$ & \\
\hline \multicolumn{4}{|l|}{ Insurance status } \\
\hline Private insurance & $606(64)$ & $487(66)$ & .584 \\
\hline Medicare & $377(40)$ & $219(29)$ & $<.0001$ \\
\hline No insurance & $7(1)$ & $40(5)$ & $<.0001$ \\
\hline \multicolumn{4}{|l|}{ Physician/nurse CRC recommendation } \\
\hline Doctor or nurse has discussed test for colon cancer (yes) & $840(92)$ & $461(63)$ & $<.0001$ \\
\hline Doctor has discussed CRC screening (yes) & $718(69)$ & $330(45)$ & $<.0001$ \\
\hline Doctor has recommended CRC screening & $788(85)$ & $373(51)$ & $<.0001$ \\
\hline Age of first recommendation (years) & $53(8.09)$ & $53(7.39)$ & .232 \\
\hline Age of most recent recommendation (years) & $60(7.10)$ & $58(7.10)$ & $<.0001$ \\
\hline Doctor recommended CRC screening because of symptoms & $274(30)$ & $57(8)$ & $<.0001$ \\
\hline Age of first recommendation (years) & $54(9.90)$ & $51(10.17)$ & .027 \\
\hline Age of most recent recommendation (years) & $60(8.18)$ & $57(9.18)$ & .030 \\
\hline Recency of recommendation (years) & $2.6(2.7)$ & $2.7(4.6)$ & .887 \\
\hline
\end{tabular}

Values provided as. 
Table 3. Colorectal Cancer (CRC) Screening Tests Recommended by Physician and Completed by Group

\begin{tabular}{|c|c|c|c|c|}
\hline Screening Tests & Variables & Ineligible $(\mathrm{n}=942)$ & Eligible $(\mathrm{n}=743)$ & $P$ \\
\hline \multirow[t]{3}{*}{ FOBT } & Doctor ever recommended & $465(49)$ & $178(24)$ & $<.0001$ \\
\hline & Returned within past year* & $98(24)$ & $0(0)$ & $<.0001$ \\
\hline & Returned more than a year ago* & $317(76)$ & $128(100)$ & \\
\hline \multirow[t]{3}{*}{ FIT } & Doctor ever recommended & $137(15)$ & $51(7)$ & $<.0001$ \\
\hline & Returned within past year* & $30(25)$ & $0(0)$ & .0021 \\
\hline & Returned more than a year ago* & $92(75)$ & $31(100)$ & \\
\hline \multirow[t]{3}{*}{ Flexible Sigmoidoscopy } & Doctor ever recommended & $208(22)$ & $76(10)$ & $<.0001$ \\
\hline & Completed with past 5 years* & $79(42)$ & $0(0)$ & $<.0001$ \\
\hline & Completed more than 5 years ago* & $110(58)$ & 56() & \\
\hline \multirow[t]{3}{*}{ Colonoscopy } & Doctor ever recommended & $902(96)$ & $269(36)$ & $<.0001$ \\
\hline & Completed within past 10 years* & $897(99.8)$ & $0(0)$ & $<.0001$ \\
\hline & Completed more than 10 years ago* & $2(0.2)$ & $76(100)$ & \\
\hline \multirow[t]{3}{*}{ Barium Enema } & Doctor ever recommended & $163(17)$ & $50(7)$ & $<.0001$ \\
\hline & Completed with past 5 years* & $44(28)$ & $0(0)$ & $<.0001$ \\
\hline & Completed more than 5 years ago* & $113(72)$ & $48(100)$ & \\
\hline
\end{tabular}

Values provided as $\mathrm{n}(\%)$.

${ }^{*}$ For each specific modality, the number of subjects who completed the test at any one time was used as the total subjects in the $\chi^{2}$ test and excluded missing subjects.

FIT, fecal immunochemical test; FOBT, fecal occult blood test.

tion technology staff were unable to discern which patients in each practice had completed any form of CRC screening. So, individuals who were truly ineligible for the study were invited to participate and then, based on self-report, were excluded from the study and notified by letter.

After the intensive recruitment process, 743 of 8372 potential subjects (9\%) were eligible for CRC screening and enrolled in the study. We based eligibility on self-reported CRC screening status to save significant time and money with recruitment, given that our practice-based research network is spread over the state of Iowa, with 2 offices in South Dakota. Our goal was to have 100 subjects eligible from each clinic, for a total of 1500 from the original 15 clinics; half that number were recruited. One of the primary reasons that this CRC screening trial did not meet recruitment goals was because many of the potential subjects were up to date with screening and thus ineligible. Neither the offices with electronic medical records or those with paper records were able to generate information regarding colonoscopy screening. Paper records require manual searches and electronic medical records generally do not have a search utility to provide the CRC screening data. ${ }^{30}$ Data to be extracted from electronic medical records is only as accurate as that which is entered. The data needs to be detailed, specific, and targeted for health care outcomes.

The practice and patient recruitment process was onerous, despite the creation of a versatile tracking database. The recruitment experience may provide several useful lessons for investigators undertaking practice-based research network intervention trials, such as knowing the capabilities and limitations of electronic medical record data and human error in manipulating databases.

At the practice level, several factors may have prevented attainment of planned recruitment numbers. Although we requested that patient lists include active patients living in their own home, we received lists that contained deceased individuals, individuals with addresses in nonadjacent states, and individuals living in nursing homes. Thus, the promise of electronic medical records for accurate lists of patients with specific conditions would have been even more challenging. Thus, University of Iowa project staff had to conduct an additional check for patients living in nursing homes and noncontiguous, out-of-state addresses before the mailings were conducted. One office sent us a list of patients from their hospital because they were not able to send an office patient list. Thus, many extra subjects were invited who were not actual patients at that particular office. 
In addition to electronic patient list subject inclusion problems, one practice exported the information incorrectly, and the first row of the database had the correct name, but the address was for a different individual. Fortunately, after the preletter mailing was sent, more than half of the letters were undeliverable because the name did not match the address. When this was corrected, the second data abstraction from that office was still incorrect because the sex for the salutation was inaccurate. This was an unusual occurrence, and a reportable event form was completed and submitted to the IRB.

Another major problem incurred in one practice: the preletter mailing to 60 subjects was discarded by the US Post Office because the subject had both a street address and post office box number. For bulk mailings, the postmaster has the discretion to discard mailings if a post office box number is not used when available. This preletter mailing included a $\$ 2$ bill incentive. Study staff was apprised of this situation by a postal worker who received the mailing and realized a $\$ 2$ bill was in the discarded envelopes. To rectify the problem for future mailings, the postmaster for each town was notified just before each bulk mailing and that \$2 was included in the envelopes.

Each participating office was unique in its enrollment in this study and facilitation of subject recruitment. We asked offices to provide patient lists (and received partial HIPAA waiver for this) because we felt that it would be very difficult for offices to conduct the mailings and track phone calls on the designated schedule. One way to improve the ease of recruitment would have been to set this up as a quality improvement study, randomly selecting the requisite number of patients from the office's patient lists and using an intention-to-treat analysis. However, this would not have allowed for the linkage of detailed baseline and follow-up data with chart review data. As IRENE offices continue to participate in practicebased research and their information technology capabilities improve, more accurate lists of potential subjects meeting specific eligibility criteria may be able to be generated.

\section{References}

1. American Cancer Society. Colorectal cancer facts and figures 2011-2013. Available at http://www.cancer. org/acs/groups/content/@epidemiologysurveilance/ documents/document/acspc-028323.pdf. Accessed November 3, 2011.

2. Centers for Disease Control and Prevention. Increased use of colorectal cancer tests-United States, 2002 and 2004. MMWR Morb Mortal Wkly Rep 2006;55(11):308-11.

3. Sankaranarayanan J, Watanabe-Galloway S, Sun J, Qiu F, Boilesen E, Thorson AG. Rurality and other determinants of early colorectal cancer diagnosis in Nebraska: a 6-year cancer registry study, 19982003. J Rural Health 2009;25(4):358-65.

4. Milgrom PM, Hujoel PP, Weinstein P, Holborow DW. Subject recruitment, retention, and compliance in clinical trials in periodontics. Ann Periodontol 1997;2(1):64-74.

5. Smith CA, Coyle ME. Recruitment and implementation strategies in randomized controlled trials of acupuncture and herbal medicine in women's health. Complement Ther Med 2006;14(1):81-6.

6. Mold JW, Aspy CA, Nagykaldi Z, Oklahoma Physicians Resource/Research Network. Implementation of evidence-based preventive services delivery processes in primary care: an Oklahoma physicians Resource/Research network (OKPRN) study. J Am Board Fam Med 2008;21(4):334-44.

7. Aspy CB, Enright M, Halstead L, Mold JW, Oklahoma Physicians Resource/Research Network. Improving mammography screening using best practices and practice enhancement assistants: an Oklahoma physicians Resource/Research network (OKPRN) study. J Am Board Fam Med 2008;21(4):326-33.

8. Bakken S, Lantigua RA, Busacca LV, Bigger JT. Barriers, enablers, and incentives for research participation: a report from the ambulatory care research network (ACRN). J Am Board Fam Med 2009;22(4):436-45.

9. Pearce KA, Love MM, Shelton BJ, et al. Cardiovascular risk education and social support (CaRESS): report of a randomized controlled trial from the Kentucky ambulatory network (KAN). J Am Board Fam Med 2008;21(4):269-81.

10. Wallerstein N, Duran B. Community-based participatory research contributions to intervention research: the intersection of science and practice to improve health equity. Am J Public Health 2010; 100(Suppl 1):S40-6.

11. Yawn BP, Pace W, Dietrich A, et al. Practice benefit from participating in a practice-based research network study of postpartum depression: a National Research Network (NRN) report. J Am Board Fam Med 2010;23(4):455-64.

12. Love MM, Pearce KA, Williamson MA, Barron MA, Shelton BJ. Patients, practices, and relationships: challenges and lessons learned from the Kentucky Ambulatory Network (KAN) CaRESS clinical trial. J Am Board Fam Med 2006;19(1):75-84.

13. Westfall JM, Mold J, Fagnan L. Practice-based research-"blue highways" on the NIH roadmap. JAMA 2007;297(4):403-6. 
14. Green LW. Translation 2 research: the roadmap less traveled. Am J Prev Med 2007;33(2):137-8.

15. Zauber AG, Lansdorp-Vogelaar I, Knudsen AB, Wilschut J, van Ballegooijen M, Kuntz KM. Evaluating test strategies for colorectal cancer screening: a decision analysis for the U.S. preventive services task force. Ann Intern Med 2008;149(9):659-69.

16. Levin B, Lieberman DA, McFarland B, et al. Screening and surveillance for the early detection of colorectal cancer and adenomatous polyps, 2008: a joint guideline from the American Cancer Society, the US Multi-Society Task Force on Colorectal Cancer, and the American College of Radiology. Gastroenterology 2008;134(5):1570-95.

17. United States Postal Service. Guide to move update. Available at http://ribbs.usps.gov/move_update/ documents/tech_guides/GuidetoMoveUpdate.pdf. Updated 2010. Accessed November 18, 2010.

18. Dillman DA. Mail and Internet surveys: the tailored design method. Hoboken, NJ: Wiley; 2000.

19. Levy BT, Nordin T, Sinift S, Rosenbaum M, James PA. Why hasn't this patient been screened for colon cancer? An Iowa research network study. J Am Board Fam Med 2007;20(5):458-68.

20. Levy BT, Dawson J, Hartz AJ, James PA. Colorectal cancer testing among patients cared for by Iowa family physicians. Am J Prev Med 2006;31(3):193201.

21. Daly JM, Levy BT, Joshi M, Xu Y, Jogerst GJ. Patient clock drawing and accuracy of self-report compared with chart review for colorectal cancer (CRC) screening. Arch Gerontol Geriatr 2010;50(3): 341-4.
22. Brawarsky P, Brooks DR, Mucci LA, Wood PA. Effect of physician recommendation and patient adherence on rates of colorectal cancer testing. Cancer Detect Prev 2004;28(4):260-8.

23. Gilbert A, Kanarek N. Colorectal cancer screening: physician recommendation is influential advice to Marylanders. Prev Med. 2005;41(2):367-379.

24. Klabunde C, Vernon SW, Nadel MR, Breen N, Seeff LC, Brown ML. Barriers to colorectal cancer screening: a comparison of reports from primary care physicians and average-risk adults. Med Care 2005;43(9):939-44.

25. Seeff LC, Nadel MR, Klabunde C, et al. Patterns and predictors of colorectal cancer test use in the adult U.S. population. Cancer 2004;100(10):2093103.

26. Klabunde C, Schenck AP, Davis WW. Barriers to colorectal cancer screening among Medicare consumers. Am J Prev Med 2006;30(4):313-9.

27. Kuwada SK. Colorectal cancer 2000. Education and screening are essential if outcomes are to improve. Postgrad Med 2000;107(5):96-8, 101-4, 107.

28. Levy BT, Daly JM, Luxon B, et al. The "Iowa Get Screened" colon cancer screening program. J Prim Care Com Health 2010;1(1):43-9.

29. Perquin DA, de Craen AJ, Helmerhorst FM. Difficulties in recruitment for a randomized controlled trial involving hysterosalpingography. Reprod Health 2006;3:5.

30. Natarajan K, Stein D, Jain S, Elhadad N. An analysis of clinical queries in an electronic health record search utility. Int J Med Inform 2010;79(7):515-22. 